\title{
Research of Low Inductance Loop Design in GaN HEMT Application
}

\author{
Sun, Bainan; Zhang, Zhe; Andersen, Michael A. E.
}

Published in:

Proceedings of the 44th Annual Conference of the IEEE Industrial Electronics Society

Link to article, DOI:

10.1109/IECON.2018.8591732

Publication date:

2018

Document Version

Peer reviewed version

Link back to DTU Orbit

Citation (APA):

Sun, B., Zhang, Z., \& Andersen, M. A. E. (2018). Research of Low Inductance Loop Design in GaN HEMT Application. In Proceedings of the 44th Annual Conference of the IEEE Industrial Electronics Society IEEE. https://doi.org/10.1109/IECON.2018.8591732

\section{General rights}

Copyright and moral rights for the publications made accessible in the public portal are retained by the authors and/or other copyright owners and it is a condition of accessing publications that users recognise and abide by the legal requirements associated with these rights.

- Users may download and print one copy of any publication from the public portal for the purpose of private study or research.

- You may not further distribute the material or use it for any profit-making activity or commercial gain

- You may freely distribute the URL identifying the publication in the public portal 


\title{
Research of Low Inductance Loop Design in GaN HEMT Application
}

\author{
Bainan Sun, Zhe Zhang, Michael A.E. Andersen \\ Dept. Electrical Engineering \\ Technical University of Denmark \\ Kongens Lyngby, Denmark \\ baisun@elektro.dtu.dk,zz@elektro.dtu.dk,ma@elektro.dtu.dk
}

\begin{abstract}
High electron mobility transistor (HEMT) is one popular research topic in the field of power electronic devices. Gallium Nitride (GaN) HEMT has the advantages of high slew rate and low operation loss. In high frequency application, parasitic impedance introduced from PCB layout can have huge impact on operation efficiency and reliability. Minimizing the loop inductance is important. In this paper, three different low inductance loop design methods are analyzed and compared in details. Numeral comparison based on finite elements analysis (FEA) is carried out. Double pulse test is carried to verify the idea. Simulation and experimental results of switching transient are given for comparison. Low inductance loop design is further corroborated by the switching loss and switching time characterization.
\end{abstract}

Keywords—GaN HEMT; low inductance loop design; parasitic extraction; switching characterization

\section{INTRODUCTION}

Along with the development of power transistor, efficiency and power density of converter has been improved dramatically through the last four decades. During this process, evolution of semiconductor material plays an important role [1]-[3]. First commercial transistor switch is introduced as silicon metal oxide semiconductor field effect transistor (Si MOSFET) in 1976 [4]. Structure and manufacturing process of Si MOSFET has been steadily optimized and improved ever since. Commercial Si MOSFET in recent year's market has already reached the theoretical boundary of Silicon semiconductor characteristic [5]. Novel semiconductor material is critical for the next generation transistor development.

Wide band gap semiconductor material, Gallium Nitride and Silicon Carbide ( $\mathrm{SiC}$ ), is widely recognized as the promising solution for high performance power transistor fabrication [6]-[8]. Benefit from wide semiconductor bandgap, HEMT has much lower parasitic capacitance and much lower on-state resistance than its Silicon counterpart [9]-[11]. Compared with SiC HEMT, GaN HEMT even shows more potential in high frequency application, which already dominates the commercial HEMT market of low to medium voltage range. Slew rate of GaN HEMT can be as high as $100 \mathrm{~V} / \mathrm{ns}$ [12]. During such high dv/dt switching condition, the parasitic inductance from PCB layout has a critical impact on the GaN HEMT switching performance [13], [14]. To fully

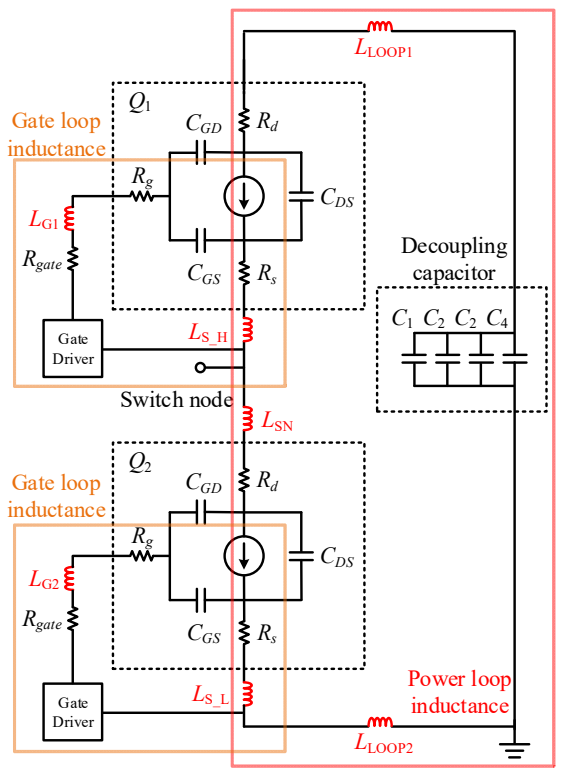

Fig. 1. Parasitic inductance in GaN HEMT switching module. harness the potential of GaN HEMT in high frequency application, research of low inductance loop design is essential.

Parasitic impedance in the half-bridge GaN HEMT switching module is shown in Fig. 1. $Q_{1}$ and $Q_{2}$ are the equivalent circuit of high side and low side GaN HEMT respectively. Parasitic capacitors inside the GaN HEMT are the chief source of power loss during the switching operation, where input capacitor $\left(C_{\mathrm{iss}}=C_{\mathrm{GS}}+C_{\mathrm{GD}}\right)$ leads to gating loss and output capacitor $\left(C_{\mathrm{oss}}=C_{\mathrm{GD}}+C_{\mathrm{DS}}\right)$ leads to switching loss [15], [16]. For PCB layout, special attention should be paid to minimize inductance of the two highlighted loops shown in Fig.1: gate loop and power loop. Gate loop inductance shall detriment the gating safety and slow down the switching speed. Power loop inductance shall increase the voltage over shoot in the transistor drain-source voltage, which affects the operation reliability as well as leads to additional switching loss. The source inductance of transistor $\left(L_{\mathrm{S}_{-} \mathrm{H}}\right.$ and $\left.L_{\mathrm{S}_{-}}\right)$is part of both gate loop inductance and power loop inductance [17]. Kelvin connection is adopted by some GaN HEMT manufacturer to decouple it from the power loop [18], [19]. Low inductance 
PCB layout design has been widely researched in academia to improve the GaN HEMT switching performance [20]-[23]. In [24], several popular low inductance loop designs are introduced and compared. Theoretical analysis is given, while quantitative analysis is absent for comparison.

In this paper, different low loop inductance design methods are analyzed and compared in details. FEA based on ANSYS $\mathrm{Q} 3 \mathrm{D}$ is given for quantitative comparison. According to the subtracted parasitic inductance, power loop is modelled in LTSpice. Based on double pulse test, simulation and experimental result are given to verify the analysis. Finally, switching loss and switching time characterization based on the low inductance loop design are given to validate the low inductance design. The paper is arranged as follows: In Section II, low inductance loop designs are introduced and compared based on FEA analysis and simulation. Experimental validation is given in Section III. Section IV concludes the paper.

\section{LOW INDUCTANCE LOOP DESIGN ANALYSIS}

\section{A. Design methodology}

For low inductance loop design, the chief idea is to minimize the total PCB track length of the power loop. Since gate loop and power loop shares the same design idea, this paper will explain the mechanism based on power loop. Three different low inductance loop designs of the half bridge GaN HEMT switching pair is shown in Fig. 1. Arrowed loop shows the current flow path during the switching pair operation.

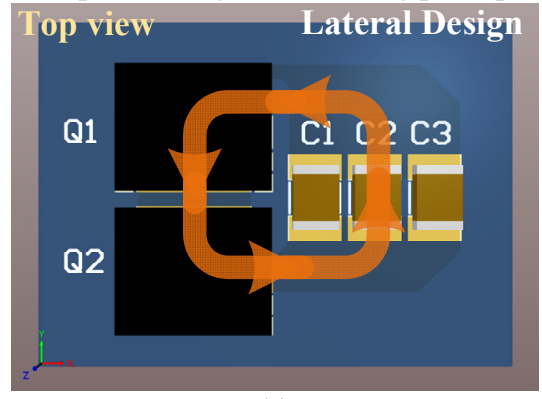

(a)

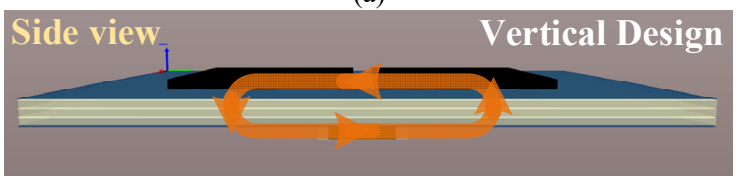

(b)

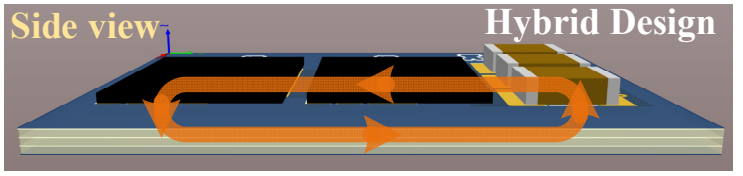

(c)

Fig. 2. Parasitic loop inductance in GaN HEMT switching pair: (a) Lateral design (top view) (b) Vertical design (side view) (c) Hybrid design (side view).

Lateral design places the GaN HEMT pair and decoupling capacitors on the same side. All the PCB tracks are located on the top layer of the board. This method is intuitive and doesn't require for multi-layer $\mathrm{PCB}$. However, the magnetic field generated by this loop is vertical to the PCB board, which may affect the operation of surrounding electric magnetic interference (EMI) sensitive components.

Vertical design solve the EMI problem by placing the $\mathrm{GaN}$ HEMT and decoupling capacitors on different side of the PCB board. Decoupling capacitors are placed right beneath the transistor pair and the length of power loop is minimized. Furthermore, current flow on each side of PCB board are in opposite direction. Magnetic field generated by the power loop is self-cancelled, which can help to reduce the parasitic inductance. Drawback of this method results from the PCB board thickness. In a multi PCB design, the total length of power loop is longer with extra middle layers, which shall increase the parasitic inductance. In addition, heat sink design is limited by the position of decoupling capacitors. Vertical design is not preferred for transistors that requires bottom side heat dissipation.

Hybrid design is a trade-off between the two methods mentioned above. GaN HEMT pair and decoupling capacitors are placed on the top layer, which forms the current charging loop. Current returned path is located at the adjacent layer beneath the top layer, where the two paths are connected by a group of vias to form a close loop. Compared with vertical design, parasitic inductance is decoupled from PCB board thickness. Power loop magnetic maintains self-cancelled. However, power loop length of hybrid design is longer than vertical design when applied in large package device routing.

\section{B. Finite Element Analysis}

Finite element analysis is a numeral method for solving engineering physic problems. To provide a numeral view and detailed comparison of the low inductance designs mentioned above, each design is applied respectively in PCB routing of the GaN HEMT switching pair, which is composed of two 650V GaN HEMT (GS66516B) and three decoupling capacitor (C1812 packaging). PCB model from Altium Designer is imported to ANASYS Q3D for FEA analysis. Excitation and sink points are added according to the current flow during switching pair operation. Parasitic inductance of each design is subtracted and shown in TABLE I.

TABLE I

POWER LOOP INDUCTANCE COMPARISON

\begin{tabular}{cccc}
\hline & Lateral Design & Vertical Design & Hybrid Design \\
\hline$L_{\mathrm{SN}}$ & $0.06 \mathrm{nH}$ & $0.06 \mathrm{nH}$ & $0.06 \mathrm{nH}$ \\
$L_{\mathrm{LOOP} 1}$ & $3 \mathrm{nH}$ & $0.46 \mathrm{nH}$ & $0.02 \mathrm{nH}$ \\
$L_{\mathrm{LOOP} 2}$ & $0.63 \mathrm{nH}$ & $0.59 \mathrm{nH}$ & $1.21 \mathrm{nH}$ \\
\hline Sum & $3.69 \mathrm{nH}$ & $1.11 \mathrm{nH}$ & $1.29 \mathrm{nH}$ \\
\hline
\end{tabular}

$L_{S N}$ is the parasitic inductance at the switching node, which is extracted from the connection cooper between the high-side transistor source pad and the low-side transistor drain pad. $L_{\mathrm{SN}}$ is the same for three designs for the identical transistor pair placement. $L_{\mathrm{LOOP} 1}$ and $L_{\mathrm{LOOP} 2}$ are the parasitic inductance between the switching pair and two terminals of the decoupling capacitors. Benefit from the magnetic field cancellation, vertical design and hybrid design can each reduces $70 \%$ parasitic inductance compared with the lateral 
design. $L_{\mathrm{LOOP} 1}$ and $L_{\mathrm{LOOP} 2}$ is highly dependent on the package of transistor pair and decoupling capacitor. $L_{\mathrm{LOOP} 1}$ and $L_{\mathrm{LOOP} 2}$ are similar in vertical design for the symmetrical components placements. In the hybrid design, $L_{\mathrm{LOOP} 2}$ is the dominant part of the loop inductance, which is resulted from the long ground returned loop in the middle layer.

C. Application Scenario Analysis

TABLE II

APPLICATION CHARACTERISTIC COMPARISON

\begin{tabular}{cccc}
\hline & Lateral Design & Vertical Design & Hybrid Design \\
\hline $\begin{array}{c}\text { Lateral } \\
\text { Space }\end{array}$ & $494.25 \mathrm{~mm}^{2}$ & $247 \mathrm{~mm}^{2}$ & $316.8 \mathrm{~mm}^{2}$ \\
\hline $\begin{array}{c}\text { Horizontal } \\
\text { Distance }\end{array}$ & 1 layer & $\begin{array}{c}\text { Board } \\
\text { thickness }\end{array}$ & 2 layer \\
\hline $\begin{array}{c}\text { Device } \\
\text { Placement }\end{array}$ & 1 side & 2 sides & 1 side \\
\hline $\begin{array}{c}\text { Magnetic } \\
\text { Cancellation }\end{array}$ & No & Yes & Yes \\
\hline
\end{tabular}

Application characteristic of three designs is shown in TABLE II. Vertical design takes up least lateral space, while, on the other hand, requires for vias through the whole PCB board to form a close conduction loop. Loop inductance of vertical design is sensitive to the board thickness. Hybrid design and lateral design are not sensitive to the board thickness. They both place all the switching pair components on the same side. Hybrid design adopts the adjacent PCB layer for ground returning which helps to maintain the magnetic cancellation.

According to the analysis above, application scenario of each design method can be summarized as follows:

- Lateral design is favored in constraint layer application.

- Vertical design is favored in large package transistor application, when the lateral inductance dominates the power loop impedance.

- Hybrid design is favored in small package GaN HEMT application, as well as transistor that requires bottom side heat dissipation.

\section{Double Pulse Test Validation}

\section{A. Double Pulse Test}

Double pulse test is a general method for GaN HEMT characterization and switching transient analysis. Minimization of loop inductance is critical for accurate loss calculation. To validate the feasibility of the researched low loop inductance design, double pulse test is carried out.

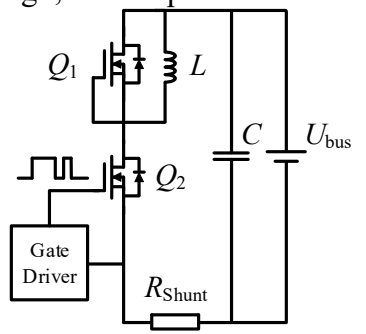

Fig. 3. Double pulse test circuit.
Double pulse test circuit can be shown as Fig. 3. Inductive load is clamped to the high side transistor. High side transistor gate is pulled down to act as the current circulating path during the low side transistor gated off. Double pulse signal is added to the gate of low side transistor. The first pulse is designed to charge the inductor to a desired load current. The second pulse provides an extra switching cycle for transient analysis and loss calculation. Test condition and test equipment are shown in TABLE III.

TABLE III

TEST CONDITION AND EQUIPMENT

\begin{tabular}{cc|cc}
\hline Condition & Value & Equipment & Model \\
\hline Voltage rate & $400 \mathrm{~V}$ & Voltage probe & LeCroy PP008 \\
\hline Current rate & $5 \sim 30 \mathrm{~A}$ & Current Probe & AP015 \\
\hline Inductive load & $0.633 \mathrm{mH}$ & $\begin{array}{c}\text { Digital } \\
\text { oscilloscope }\end{array}$ & $\begin{array}{c}\text { LeCroy } \\
\begin{array}{c}\text { 104MXs-B } \\
(10 \mathrm{~GB} / \mathrm{s})\end{array}\end{array}$ \\
\hline Gate resistor & $10 \Omega, 2 \Omega$ & Controller & TI C2000 \\
\hline
\end{tabular}

GaN HEMT GS66516B is chosen as device under test (DUT). According to analysis in the last section, hybrid design is adopted for low inductance design in both gate loop and power loop. GS66516B is driven at 400V, 5 30A switching condition. Voltage probe with ground clip is used to obtain the accurate drain-source voltage waveform. Low inductance current shunt method is used for current measurement and shunt gain factor is calibrated according to inductor current measured by current probe. The experiment setup of double pulse test is shown in Fig. 4.

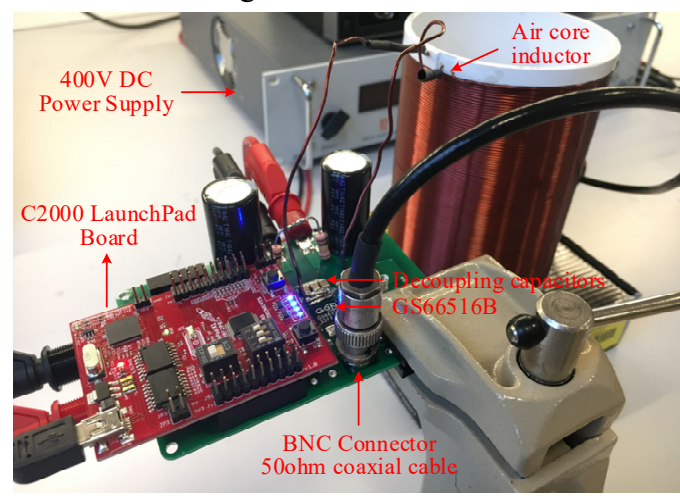

Fig. 4. Experiment setup of double pulse test.

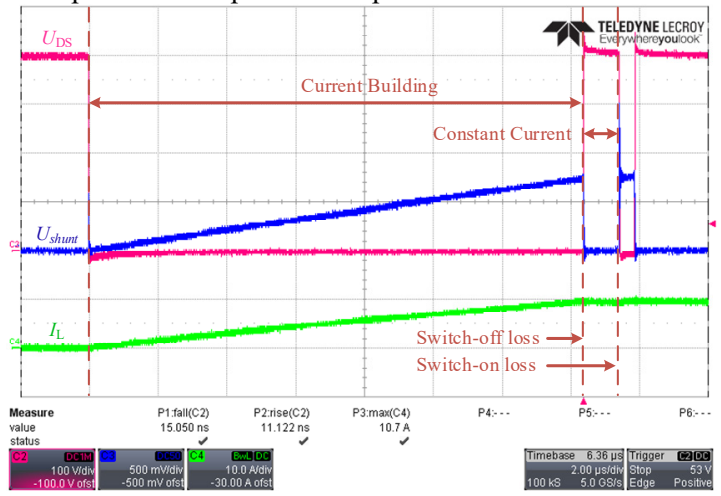

Fig. 5. Experimental result at 400V, 10A. 
Experimental result is shown in Fig. 5. During the current forming stage, inductor is charged to $10 \mathrm{~A}$ and DUT is switched off at the end. During the interval, inductor current keeps almost constant while circulating in the high side transistor. After $1 \mu \mathrm{s}$, low side DUT switches on again. Accordingly, switch on and switch off transient at the same voltage/current rate is captured at the notated point in Fig. 5.

\section{B. Switching Transient Analysis}

Transistor in double pulse test is in hard switching condition. Voltage ringing is expected to exist in drain-source waveform when the transistor is switched off. This ringing is resulted from the oscillation between transistor output capacitor and loop parasitic inductance. To validate the analysis of low inductance loop design, simulation of double pulse test is carried out in LTSpice. Parasitic inductance extracted by ANSYS Q3D is added to the simulation circuit. Simulation model of GS66516B is obtained from the manufacturer.

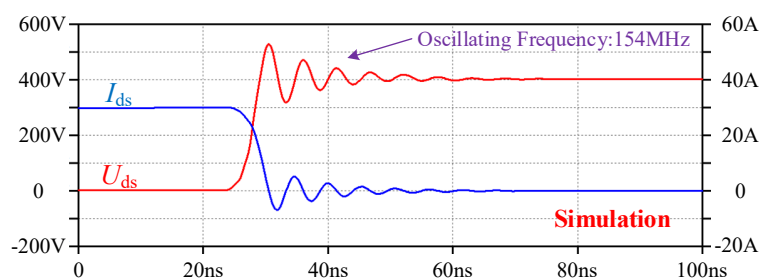

(a)

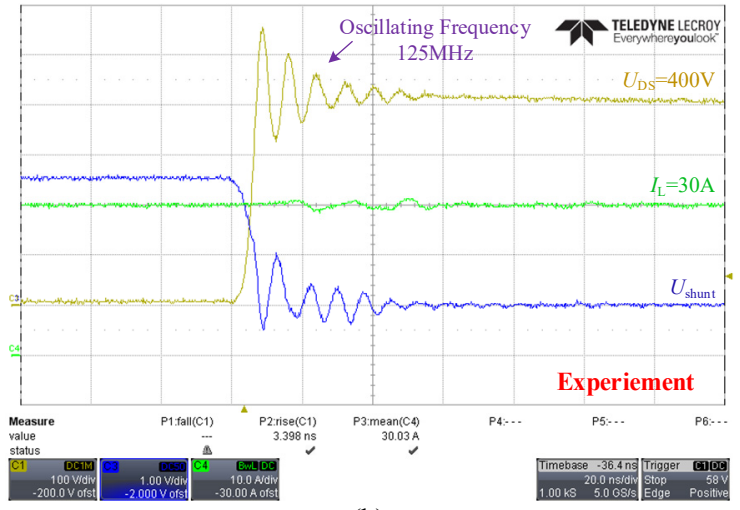

(b)

Fig. 6. Comparison of DUT switch-off transient: (a) Simulation waveform (b) Experimental waveform.

Comparison of DUT switch-off transient is shown in Fig. 6. DUT is switching at $400 \mathrm{~V}, 30 \mathrm{~A}$. Experimental results and simulation results are similar in oscillation waveform, which validates the analysis above. Benefit from the low loop inductance design, waveform shows tolerable voltage and current ringing during the switch-off transient. Oscillating frequency is $154 \mathrm{MHz}$ in simulation result and $125 \mathrm{MHz}$ in experimental result. Drain-source voltage overshoot is $32 \%$ in simulation results and $37 \%$ in experimental results.

\section{Switching Characterization}

Based on the low inductance loop design, switching characterization of GS66516B is carried out. Data captured during the switching cycle is processed in MATLAB, which is shown in Fig. 7. Switching loss is calculated according to the integral of instant loss power during the switching transient. Common mode noise coupled in the drain-source voltage and current waveform cannot be fully eliminated. However, positive and negative part of the noise signal is self-cancelled in loss calculation, which will not violate the measurement results.
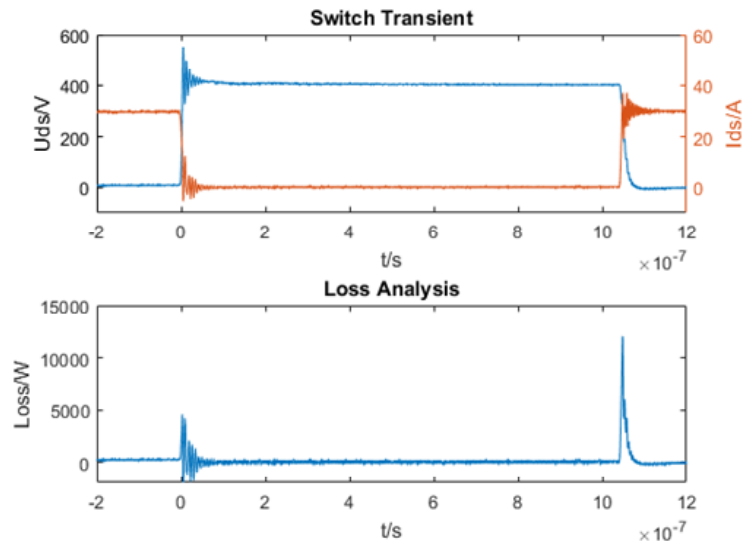

Fig. 7. Comparison of DUT switch-off transient: (a) Simulation

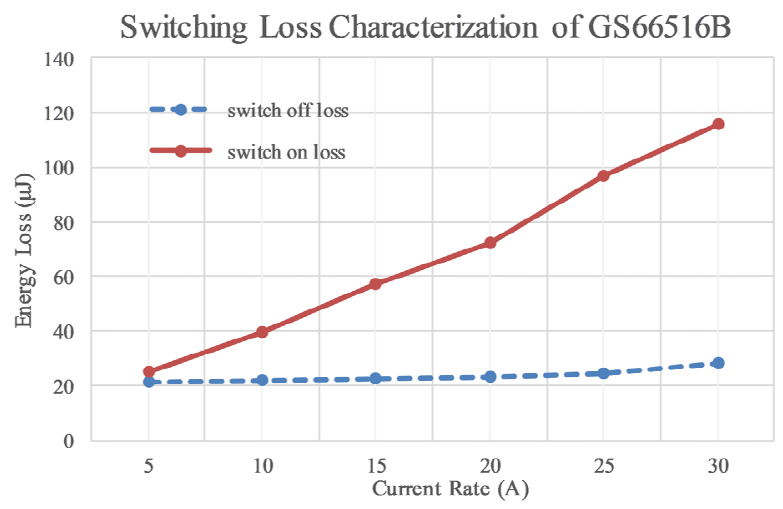

Fig. 8. Switching loss characterization.

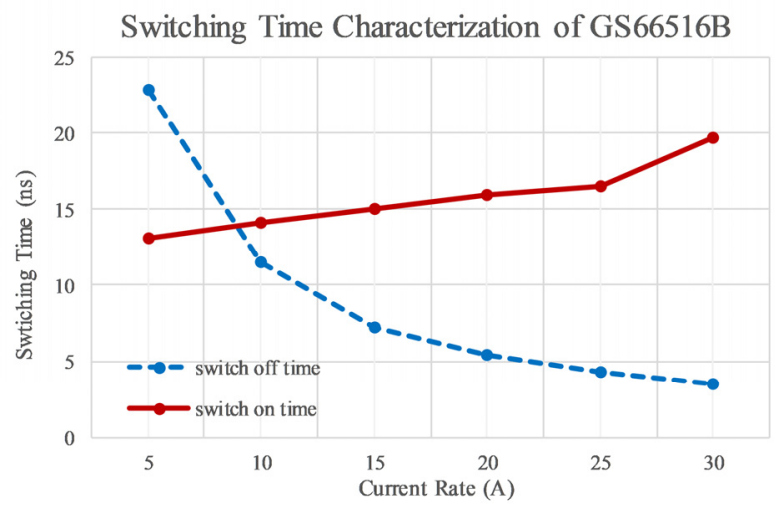

Fig. 9. Switching time characterization. 
Switching loss characterization is shown in Fig. 8. GS66516B is switching under 400V, 5 30A condition. Switching loss rises in the higher load current range. Switch-on loss is the dominant part, which is resulted from the charging and discharging process of transistor output capacitor. Compared with the data from the application note of GS66516B evaluation board, total switching loss is reduced by $20 \%$, which validates the low inductance loop design. Switching time characterization is given in Fig. 9. Switch on time increases and switch off time decreases in a higher switching current, which is resulted from the Miller plateau voltage shifting. In 30A switching condition, GS66516B can switch off in $3.47 \mathrm{~ns}$. Accordingly, slew rate of this point is $108 \mathrm{~V} / \mathrm{ns}$, which is consistent with the manufacturer datasheet.

\section{CONCLUSION}

In this paper, low inductance loop design for PCB layout is researched in details. Compared with lateral design, vertical design and hybrid design can reduce parasitic inductance by more than $70 \%$. Vertical design has even lower parasitic inductance, but is restricted by board thickness and placement of heat sink. To validate the design, double pulse test of GaN HEMT is carried out. Experimental results of the switching transient is consistent with the simulation waveform. Switching loss characterization corroborates the design effectiveness. Switching time characterization validates the high slew rate capability of GaN HEMT based on low inductance loop design.

\section{REFERENCES}

[1] U. K. Mishra, L. Shen, T. E. Kazior and Y. F. Wu, "GaN-Based RF Power Devices and Amplifiers," in Proceedings of the IEEE, vol. 96, no. 2, pp. 287-305, Feb. 2008.

[2] R. S. Pengelly, S. M. Wood, J. W. Milligan, S. T. Sheppard and W. L. Pribble, "A Review of GaN on SiC High Electron-Mobility Power Transistors and MMICs," in IEEE Transactions on Microwave Theory and Techniques, vol. 60, no. 6, pp. 1764-1783, June 2012.

[3] N. Ikeda et al., "GaN Power Transistors on Si Substrates for Switching Applications," in Proceedings of the IEEE, vol. 98, no. 7, pp. 11511161, July 2010.

[4] Lidow, Alex, Johan Strydom, Michael De Rooij, and David Reusch. GaN transistors for efficient power conversion. John Wiley \& Sons, 2014.

[5] K. Li, P. L. Evans and C. M. Johnson, "Characterisation and Modeling of Gallium Nitride Power Semiconductor Devices Dynamic On-State Resistance," in IEEE Transactions on Power Electronics, vol. 33, no. 6, pp. 5262-5273, June 2018

[6] H. Wang, J. Wei, R. Xie, C. Liu, G. Tang and K. J. Chen, "Maximizing the Performance of $650-\mathrm{V}$ p-GaN Gate HEMTs: Dynamic RON Characterization and Circuit Design Considerations," in IEEE Transactions on Power Electronics, vol. 32, no. 7, pp. 5539-5549, July 2017.

[7] J. Lautner and B. Piepenbreier, "Analysis of GaN HEMT switching behavior," 2015 9th International Conference on Power Electronics and ECCE Asia (ICPE-ECCE Asia), Seoul, 2015, pp. 567-574.

[8] W. Kangping et al., "Analytical loss model of low voltage enhancement mode GaN HEMTs," 2014 IEEE Energy Conversion Congress and Exposition (ECCE), Pittsburgh, PA, 2014, pp. 100-105..
[9] M. Orabi and A. Shawky, "Proposed Switching Losses Model for Integrated Point-of-Load Synchronous Buck Converters," in IEEE Transactions on Power Electronics, vol. 30, no. 9, pp. 5136-5150, Sept. 2015.

[10] K. Kruse, M. Elbo and Z. Zhang, "GaN-based high efficiency bidirectional DC-DC converter with $10 \mathrm{MHz}$ switching frequency," 2017 IEEE Applied Power Electronics Conference and Exposition (APEC), Tampa, FL, 2017, pp. 273-278.

[11] J. C. Hernandez, L. P. Petersen and M. A. E. Andersen, "Characterization and evaluation of $600 \mathrm{~V}$ range devices for active power factor correction in boundary and continuous conduction modes," 2015 IEEE Applied Power Electronics Conference and Exposition (APEC), Charlotte, NC, 2015, pp. 1911-1916.

[12] V. S. Nguyen, L. Kerachev, P. Lefranc and J. C. Crebier, "Characterization and Analysis of an Innovative Gate Driver and Power Supplies Architecture for HF Power Devices With High dv/dt," in IEEE Transactions on Power Electronics, vol. 32, no. 8, pp. 6079-6090, Aug. 2017.

[13] Z. Zhang, F. Wang, L. M. Tolbert, B. J. Blalock and D. J. Costinett, "Active gate driver for fast switching and cross-talk suppression of $\mathrm{SiC}$ devices in a phase-leg configuration," 2015 IEEE Applied Power Electronics Conference and Exposition (APEC), Charlotte, NC, 2015, pp. 774-781.

[14] B. Sun, R. Burgos, X. Zhang and D. Boroyevich, "Active dv/dt control of $600 \mathrm{~V} \mathrm{GaN}$ transistors," 2016 IEEE Energy Conversion Congress and Exposition (ECCE), Milwaukee, WI, 2016, pp. 1-8.

[15] Yuhui Chen, F. C. Lee, L. Amoroso and Ho-Pu Wu, "A resonant MOSFET gate driver with efficient energy recovery," in IEEE Transactions on Power Electronics, vol. 19, no. 2, pp. 470-477, March 2004.

[16] J. V. P. S. Chennu and R. Maheshwari, "Study on Resonant Gate Driver circuits for high frequency applications," 2016 IEEE 6th International Conference on Power Systems (ICPS), New Delhi, 2016, pp. 1-6.

[17] W. Zhang, X. Huang, F. C. Lee and Q. Li, "Gate drive design considerations for high voltage cascode GaN HEMT," 2014 IEEE Applied Power Electronics Conference and Exposition - APEC 2014, Fort Worth, TX, 2014, pp. 1484-1489.

[18] E. A. Jones, F. Wang, D. Costinett, Z. Zhang and B. Guo, "Cross conduction analysis for enhancement-mode $650-\mathrm{V}$ GaN HFETs in phase-leg topology," 2015 IEEE 3rd Workshop on Wide Bandgap Power Devices and Applications (WiPDA), Blacksburg, VA, 2015, pp. 98-103.

[19] J. Acuña, A. Seidel and I. Kallfass, "Design and implementation of a Gallium-Nitride-based power module for light electro-mobility applications," 2017 IEEE Southern Power Electronics Conference (SPEC), Puerto Varas, 2017, pp. 1-6.

[20] H. Peng, R. Ramabhadran, R. Thomas and M. J. Schutten, "Comprehensive switching behavior characterization of high speed Gallium Nitride E-HEMT with ultra-low loop inductance," 2017 IEEE 5th Workshop on Wide Bandgap Power Devices and Applications (WiPDA), Albuquerque, NM, 2017, pp. 116-121.

[21] A. Kulkarni, A. Gupta and S. K. Mazumder, "Resolving Practical Design Issues in a Single-Phase Grid-Connected GaN-FET-Based Differential-Mode Inverter," in IEEE Transactions on Power Electronics, vol. 33, no. 5, pp. 3734-3751, May 2018.

[22] A. Gupta and S. K. Mazumder, "GaN-FET based grid-connected solar microinverter: Some design insights," 2017 IEEE 5th Workshop on Wide Bandgap Power Devices and Applications (WiPDA), Albuquerque, NM, 2017, pp. 233-237.

[23] D. Reusch and J. Strydom, "Understanding the Effect of PCB Layout on Circuit Performance in a High-Frequency Gallium-Nitride-Based Point of Load Converter," in IEEE Transactions on Power Electronics, vol. 29, no. 4, pp. 2008-2015, April 2014. 